\title{
EFEKTIFITAS LAYANAN E-FILING TERHADAP WAJIB PAJAK ORANG PRIBADI DI KANTOR PELAYANAN PAJAK PRATAMA MALANG SELATAN
}

\author{
Gella Intan Adestya ${ }^{1}$, Saman $^{2}$ \\ ${ }^{1}$ Universitas Merdeka Malang, Jl. Terusan Raya Dieng 62-64, Malang, 5146, Indonesia \\ ${ }^{2}$ Universitas Merdeka Malang, Jl. Terusan Raya Dieng 62-64, Malang, 5146, Indonesia
}

\begin{abstract}
This study aims to evaluate e-filing services by tax authorities to individual taxpayers, know the level of effectiveness based on the data of effective individual taxpayers who use e-filing, and know the effectiveness of the target and the realization of the use of e-filing whether it has been realized properly.Data collection techniques in this study are by interview and documentation. The data analysis technique used is qualitative and quantitative descriptive analysis. The results of this study

are that the quality of e-filing services in South Malang KPP Pratama has been very good, the effectiveness of using e-filing based on effective Personal Taxpayer data is still not effective because there are still significant differences with the submission of Annual Tax Returns manually but already has increased every year, the target and realization of submission of Annual Tax Returns for Individual Taxpayers using efiling has been achieved well and continues to increase for each year.
\end{abstract}

Keywords:

Quality of Service, Effectiveness, E-filing, Annual Notice.

Kata Kunci:

Kualitas Layanan, Efektifitas, e-filing, Surat Pemberitahuan Tahunan

\section{ABSTRAK}

Penelitian ini bertujuan untuk (1) mengevaluasi layanan e-filing oleh fiskus kepada Wajib Pajak Orang Pribadi, (2)mengevaluasi tingkat efektifitas Wajib Pajak Orang Pribadi yang menggunakan $e$-filing, dan (3) menganalisis target dan realisasi penggunaan e-filing dalam melaporkan SPT Tahunan wajib pajak orang pribadi. Teknik pengumpulan data dalam penelitian ini yaitu wawancara dan dokumentasi. Sedangkan teknik analisis data yang digunakan adalah analisis deskriptif kualitatif dan kuantitatif. Hasil dari penelitian ini adalah kualitas pelayanan e-filing di KPP Pratama Malang Selatan sudah sangat bagus, tingkat efektifitas penggunaan e-filing Wajib Pajak Orang Pribadi belum efektif karena masih terdapat perbedaan yang cukup besar dengan penyampaian SPT Tahunan secara manual namun sudah mengalami peningkatan setiap tahunnya, target dan realisasi penyampaian SPT Tahunan Wajib Pajak Orang Pribadi menggunakan e-filing sudah tercapai dengan baik dan terus mengalami peningkatan untuk setiap tahunnya. 


\section{PENDAHULUAN}

Pelaksanaan pembangunan di Negara ini bertujuan untuk meningkatkan kesejahteraan masyarakat. Salah satu sumber penerimaan negara berasal dari pajak. Pajak merupakan suatu hal yang penting bagi Negara, mengingat sebagian besar Anggaran Pendapatan Belanja Negara (APBN) bersumber dari penerimaan pajak sehingga pemerintah selalu mengevaluasi dan menyempurnakan Undang-undang perpajakan untuk meningkatkan penerimaan pajak. Selain itu pemerintah juga berupaya untuk meningkatkan kesadaran wajib pajak dalam melakukan kewajiban perpajakan., melalui sosialisasi peraturan pajak kepada wajib pajak, baik wajib pajak pribadi maupun wajib pajak badan. Pemerintah terus berupaya untuk meningkatkan pemungutan pajak, yaitu dengan cara meningkatkan kualitas pelayanan oleh fiskus kepada Wajib Pajak dan menerapkan kebijakan pelaporan SPT Tahunan dengan menggunakan sistem e-filling. Upaya diharapkan dapat meningkatan kualitas pelayanan kepada wajib pajak, sehingga dapat meningkatkan penerimaan pajak.

Pelaporan SPT Tahunan dengan e-fillingmerupakan layanan perpajakan untuk melaporkan dan menyampaikan Surat Pemberitahuan Tahunan secara online. Hal ini merupakan bentuk modernisasi dari sistem perpajakan dan wajib Pajak tidak perlu lagi datang ke Kantor Pajak untuk melaporkan SPT Tahunan. Pelaporan SPT Tahunan dengan menggunakan $e$-filingdapat meningkatkan efektifitas pelayanan kepada wajib pajak. Penelitian tentang Efektifitas Layanan E-filling Terhadap Wajib Pajak Orang Pribadi di Kantor Pelayanan Pajak (KPP) Pratama Malang Selatan, penting untuk dilakukan untuk menilai layanan e-filling Wajib pajak pribadi, apakah sudah efektif atau belum. Mengingat penerapan pelaporan SPT Tahunan secara online masih belum maksimal dilakukan oleh wajib pajak orang pribadi.

Penelitian ini bertujuan untuk mengevaluasi layanan e-filing oleh fiskus kepada Wajib Pajak Orang Pribadi, mengevaluasi tingkat efektifitas Wajib Pajak Orang Pribadi yang menggunakan e-filing, dan menganalisis target dan realisasi penggunaan $e$-filing dalam melaporkan SPT Tahunan wajib pajak orang pribadi di KPP Pratama Malang Selatan.

a. Pajak

Menurut Undang-Undang nomor 16 tahun 2009 tentang perubahan keempat atas Undang-Undang nomor 6 tahun 1983 tentang Ketentuan Umum dan Tata Cara Perpajakan pada Pasal 1 Ayat 1 berbunyi pajak adalah kontribusi wajib kepada Negara yang terutang oleh orang pribadi atau badan yang bersifat memaksa berdasarkan Undang-Undang, dengan tidak mendapatkan imbalan secara langsung dan digunakan untuk keperluan Negara bagi sebesar-besarnya kemakmuran rakyat.

b. Wajib Pajak

Wajib Pajak adalah orang pribadi atau badan yang menurut ketentuan peraturan perundang-undangan perpajakan ditentukan untuk melakukan kewajiban perpajakan, termasuk pemungut pajak atau pemotong pajak tertentu.

c. Surat Pemberitahuan Tahunan (SPT)

Adalah surat yang digunakan Wajib Pajak untuk melaporkan perhitungan serta pembayaran pajak, objek pajak dan bukan objek pajak, penghasilan serta harta dan kewajban lainnya yang sesuai dengan peraturan perundang-undangan perpajakan.

\section{d. Pelayanan Publik}

Pengertian pelayanan publik menurut Pasal 1 Undang-Undang Nomor 25 Tahun 2009 adalah kegiatan atau rangkaian kegiatan dalam rangka pemenuhan kebutuhan pelayanan sesuai dengan peraturan perundang-undangan bagi setiap warga Negara dan penduduk atas barang, jasa, dan/atau pelayanan administratif yang disediakan oleh penyelenggara pelayanan publik.

\section{e. E-filing}

Pengertian e-filing menurut Peraturan Direktur Jenderal Pajak Nomor PER-01/PJ/2014 adalah sebagai berikut : E-filing adalah suatu cara penyampaian SPT Tahunan secara elektronik yang dilakukan secara online dan real time melalui internet pada website Direktorat Jenderal Pajak (www.pajak.go.id) atau penyedia jasa aplikasi atau application service provider (ASP) 


\section{f. Kepatuhan Wajib Pajak}

Adalah tindakan dari Wajib Pajak yang melakukan semua kewajiban perpajakan dengan menggunakan hak perpajakannya tetapi tetap taat pada peraturan perundang-undangan yang berlaku.

\section{METODE}

\section{Variabel Penelitian}

Layanan e-filing merupakan layanan yang diberikan untuk pelaporan SPT, guna meningkatkan efektifitas pelayanan dan meningkatkan kepuasan Wajib Pajak.Tingkat pelayanan yang bagus bisa diukur dengan pelayanan yang diberikan oleh petugas pajak (sistemnya mudah diakses).Tingkat kepatuhanWajib Pajak bisa diukur dengan jumlah Wajib Pajak yang menyampaikan dan melaporkan SPT Tahunan dengan tepat waktu serta meningkatnya jumlah pelaporan SPT untuk tiap tahunnya.Sedangkan untuk tingkat efektifitas diukur berdasarkan jumlah Wajib Pajak Orang Pribadi yang menggunakan e-filing dan dibandingkan dengan keseluruhan Wajib Pajak Orang Pribadi.

\section{Jenis Data}

Jenis data dalam penelitian ini adalah data primer berupa wawancara dan data sekunder berupa data yang berkaitan dengan wajib pajak pribadi SPT Tahunan wajib pajak orang pribadi di KPP Pratama Malang Selatan di Kantor

\section{Teknik Analisis Data}

Teknik analisis data menggunakan analisis deskriptif kualitatif dan kuantitatif. Langkah-langkahnya adalah sebagai berikut:

1. Mengevaluasi kualitas pelayanan fiskus terhadap Wajib Pajak Orang Pribadi terkait dengan pelayanan e-filing dalam pelaporan SPT Tahunan pada Kantor Pelayanan Pajak Pratama Malang Selatan.

2. Menganalisis tingkat kepatuhan Wajib Pajak Orang Pribadi terhadap pelaporan SPT Tahunan yang menggunakan $e$-filing pada Kantor Pelayanan Pajak Pratama Malang Selatan dengan cara melihat tingkat kepatuhan Wajib Pajak setiap tahunnya.

3. Mengevaluasi tingkat pelaporan SPT Tahunan menggunakan e-filing untuk mengukur tingkat efektifitasnya.

Efektifitas adalah tingkat pencapaian antara realisasi dari pelaporan SPT Tahunan menggunakan $e$ filing yang bisa menunjukkan apakah realisasi yang dihasilkan sudah sesuai dengan target yang ditentukan. Untuk mengukur efektifitas realiisasi dari pendapatan atas target yang ditentukan, maka digunakan rumus perhitungan sebagai berikut :

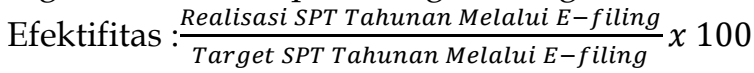

\section{Hasil Penelitian}

Pelayanan yang diberikan oleh fiskus kepada Wajib Pajak pasti tidaklah sama, namun tergantung oleh apa yang dibutuhkan oleh Wajib Pajak itu sendiri. Ada atau tidak adanya perbedaan pelayanan tergantung dari bagaimana kebijakan yang diterapkan oleh kantor itu sendiri. Sementara pada KPP Pratama Malang Selatan ini terdapat perbedaan dalam pelayanannya.

Terdapat ruang untuk asistensi e-filing yang letaknya di bagian ruang rapat bagian depan. Ruangan ini lebih diprioritaskan bagi para pensiunan, sehingga mereka tidak perlu lagi untuk menaiki tangga. Di sana mereka akan dibantu oleh fiskus yang bertugas untuk melaporkan SPT secara $e$-filing. Bagi yang masih mengalami kesusahan bagaimana cara mengisi dan melaporkan SPT maka bisa menuju ke ruang asistensi e-filing yang terletak di lantai 2. Namun di ruangan tersebut lebih diprioritaskan untuk wajib pajak yang berbentuk PT, CV, dan karyawan yang non pensiunan. 
Sedangkan untuk penerimaan yang secara langsung di kantor, KPP Pratama Malang Selatan ini terdapat petugas yang diberi nama yaitu Satgas (satuan tugas penerimaan SPT). Di sini yang termasuk menjadi satgas adalah pegawai dari petugas pajak itu sendiri yang mendapat piket.Di mana petugas tersebut dibagi menjadi 2 yaitu sebagai peneliti dan sebagai penerima.Biasanya pada saat pelaporan SPT juga ada dari mahasiswa yang mengikuti perkumpulan di bidang perpajakan yang ikut membantu petugas perpajakan di KPP Pratama Malang Selatan ini.

Dengan adanya kebijakan pelayanan yang bagus seperti ini, maka akan meningkatkan penerimaan pajak, karena dengan adanya sistem konsultasi yang seperti ini akan mempermudah Pajib Pajak. Setelah SPT masuk, maka akan diteliti lagi kebenaran dari uji materiilnya. Karena setelah selesai diberlakukannya program tax amnesty ada pengakuan harta secara sukarela. Di mana wajib pajak yang tidak mengikuti program tax amnesty bisa mengakui berapa banyak jumlah hartanya dan tidak akan dikenakan UndangUndang yang berat seperti misalnya denda sebesar $200 \%$ serta dijadikan penghasilan, namun wajib pajak harus membayar dengan sukarela sebelum ditemukan oleh fiskus.

Hal ini merupakan salah satu cara untuk meningkatkan jumlah penerimaan pajak di Negara ini. Menurut berbagai sumber, dikatakan bahwa bentuk pelayanan yang diberikan oleh fiskus ada yang baik dan juga tidak. Contoh dari pelayanan yang tidak baik seperti pada saat fiskus ditanya tetapi dia tidak bisa memberikan pelayanan dengan nyaman sehingga hal ini menyebabkan mungkin wajib pajak menjadi merasa tidak puas dan tidak mengerti tentang hal perpajakan, sehingga wajib pajak tidak melakukan kewajiban pajaknya.

Karena bisa saja Wajib Pajak menjadi berpikir bahwa menjalankan kewajiban perpajakan saja sudah susah ditambah lagi dengan rasa kurang puasnya terhadap pelayanan yang diberikan oleh fiskus. Namun apabila kualitas pelayanan yang diberikan oleh fiskus kepada Wajib Pajak sudah bagus, maka Wajib Pajak akan lebih patuh lagi dalam melaksanakan kewajiban perpajakannya.

\section{Hasil Analisis Penelitian}

1. Karakteristik Wajib Pajak

Jumlah Wajib Pajak Orang Pribadi Yang Terdaftar Di KPP Pratama Malang Selatan Pada Tahun 2015-2017

\begin{tabular}{|l|c|c|c|}
\hline WP OP & 2015 & 2016 & 2017 \\
\hline Non efektif & 23.629 & 23.726 & 23.769 \\
\hline Normal & 74.077 & 79.753 & 84.472 \\
\hline Total & 97.706 & 103.479 & 108.241 \\
\hline
\end{tabular}

Sumber : KPP Pratama Malang Selatan

2. Data Jumlah Pelaporan SPT Tahunan

Jumlah Pelaporan SPT Tahunan Orang Pribadi Di KPP Pratama Malang Selatan Pada Tahun 2015-2017

\begin{tabular}{|l|l|l|l|}
\hline Jenis SPT & 2015 & 2016 & 2017 \\
\hline SPT Tahunan PPh Orang Pribadi & 41.700 & 43.596 & 38.601 \\
\hline Grand Total & 41.700 & 43.596 & 38.601 \\
\hline
\end{tabular}

Sumber : KPP Pratama Malang Selatan 
Jumlah Wajib Pajak Orang Pribadi Yang Melaporkan SPT Tahunan Menggunakan E-filing Di KPP Pratama Malang Selatan Pada Tahun 2015-2017

\begin{tabular}{|l|c|c|c|}
\hline \multirow{2}{*}{ e-filing } & \multicolumn{3}{|c|}{ Tahun } \\
\cline { 2 - 4 } & 2015 & 2016 & 2017 \\
\hline Target & 8.654 & 20.579 & 19.629 \\
\hline Realisasi & 11.130 & 21.037 & 27.308 \\
\hline
\end{tabular}

Sumber : KPP Pratama Malang Selatan

Jumlah Wajib Pajak Orang Pribadi yang melaporkan SPT Tahunannya menggunakan $e$-filing dan secara manual

\begin{tabular}{|c|c|c|c|c|c|c|}
\hline No & Tahun & $\begin{array}{c}\text { Total } \\
\text { WPOP }\end{array}$ & $\begin{array}{c}\text { WPOP } \\
\text { Efektif }\end{array}$ & $\begin{array}{c}\text { WPOP } \\
\text { Tidak } \\
\text { Efektif }\end{array}$ & $\begin{array}{c}\text { Menggunakan E- } \\
\text { filing }\end{array}$ & $\begin{array}{c}\text { Secara } \\
\text { Manual }\end{array}$ \\
\hline 1 & 2015 & 97.706 & 74.077 & 23.629 & 11.130 & 62.947 \\
\hline 2 & 2016 & 103.479 & 79.753 & 23.726 & 21.037 & 58.716 \\
\hline 3 & 2017 & 108.241 & 84.472 & 23.679 & 27.308 & 57.434 \\
\hline
\end{tabular}

Sumber : KPP Pratama Malang Selatan

\section{Pembahasan}

1. Evaluasi Kualitas pelayanan Terhadap Fiskus

Kualitas pelayanan yang diberikan oleh fiskus kepada Wajib Pajak sudah efektif sesuai dengan yang diharapkan oleh para Wajib Pajak. Hal ini dibuktikan dengan banyaknya fiskus yang siap untuk melayani Wajib Pajak dengan baik dan selain itu ketika menjelang waktu pelaporan SPT Tahunannya juga disediakan banyaknya satgas yang dijadwalkan untuk piket dalam setiap harinya sebanyak kurang lebih 19 orang serta dibantu pula oleh para mahasiswa dari beberapa kampus yang ada di Kota Malang yang tergabung dalam perkumpulan perpajakan.

Namun, masih banyak Wajib Pajak terutama untuk para Wajib Pajak pensiunan yang tidak bisa mengisi SPT Tahunan secara online. Hal ini disebabkan karena masih banyak Wajib Pajak yang tidak paham internet (gaptek). Agar Wajib Pajak memahami bagaimana cara mengisi SPT Tahunan secara online, pihak KPP telah memberikan solusi melalui beberapa cara seperti terdapatnya ruang asistensi di KPP dan sering diadakannya sosialisasi tentang e-fiing di berbagai sekolah, mall, pasar, media sosial instagram, dan pada saat car free day.

Selain itu di pihak KPP juga bersedia menjelaskan terlebih dahulu secara langsung tentang pemahaman internet apabila Wajib Pajak datang langsung ke kantor dan untuk para pensiunan yang sudah tidak kuat fisiknya maka tidak perlu untuk naik ke lantai atas namun cukup menuju ke ruang yang ada di bawah saja. Dengan adanya kebijakan pelayanan yang bagus seperti ini maka akan memudahkan para Wajib Pajak untuk mengisi SPT Tahunan dengan menggunakan $e$-fiing.

Akan tetapi pada saat menjelang batas akhir pelaporan SPT Tahunan Orang Pribadi banyak yang baru melaporkan secara e-filing sehingga menyebabkan server dari pusat mengalami gangguan (error) karena overload. Karena server error pada saat menggunakan $e$-filing menyebabkan Wajib Pajak tidak bisa mengakses DJP online secara lancar.

Menurut pihak KPP, KPP tidak bisa melakukan banyak hal ketika terjadi gangguan pada server selain menunggu beberapa saat sampai sistemnya kembali normal. Hal ini juga menyebabkan 
gangguan yang sama bisa saja terjadi di beberapa tempat dalam waktu bersamaan. Sebenarnya pihak DJP telah menambahkan server, tetapi pada kenyataannya masih saja sering terjadi error. Solusi untuk menghindari kejadian seperti ini maka seharusnya fiskus menghimbau agar Wajb Pajak sadar untuk melaporkan SPT Tahunan dengan menggunakan e-filing sebelum masa pelaporan SPT Tahunan berakhir sehingga server error bisa dihindari dan wajib pajak bisa lebih patuh lagi.

2. Analisis tingkat efektifitas penggunaan e-filing berdasarkan data Wajib Pajak Orang Pribadi efektif di KPP Pratama Malang Selatan.

Analisis Efektifitas Penggunaan E-filing Berdasarkan Data Wajib Pajak Orang Pribadi Yang Efektif Pada Tahun 2015-2017

\begin{tabular}{|c|c|c|c|c|}
\hline Tahun & $\begin{array}{c}\text { WPOP } \\
\text { Efektif }\end{array}$ & $\begin{array}{c}\text { Menggunakan E- } \\
\text { filing }\end{array}$ & Persentase & Tingkat efektif \\
\hline 2015 & 74.077 & 11.130 & $15 \%$ & Tidak efektif \\
\hline 2016 & 79.753 & 21.037 & $26 \%$ & Tidak efektif \\
\hline 2017 & 84.472 & 27.038 & $32 \%$ & Tidak efektif \\
\hline
\end{tabular}

Sumber : Data Diolah, 2019

Berdasarkan data di atas disimpulkan bahwa penggunaan e-filing untuk Wajib Pajak Orang Pribadi masih belum efektif meskipun jumlah Wajib Pajak Orang Pribadi efektif yang terdaftar di KPP Pratama Selatan mengalami peningkatan setiap tahunnya. Adanya peningkatan ini, adalah bukti bahwa jumlah pelaporan SPT Tahunan juga pasti meningkat setiap tahunnya. Hal ini terbukti bahwa pada tahun 2016 terjadi peningkatan dari tahun sebelumnya meskipun pada tahun 2017 sempat mengalami penurunan.

Selain itu berdasarkan data yang diperoleh juga bisa disimpulkan bahwa jumlah Wajib Pajak Orang Pribadi yang melaporkan SPT Tahunannya menggunakan $e$-filing terus mengalami peningkatan setiap tahunnya. Pada tahun 2015 sebanyak 11.130 jika dibandingkan dengan Wajib Pajak Orang Pribadi efektif yang terdaftar di KPP Pratama Selatan pada tahun yang sama yaitu sebanyak 74.077, tahun 2016 yang menggunakan $e$-filing sebanyak 21.037 dan jumlah Wajib Pajak Orang Pribadi efektif sebanyak 79.753, dan pada tahun 2017 jumlah Wajib Pajak Orang Pribadi yang menggunakan e-filing sebanyak 27.308 sedangkan jumlah Wajib Pajak Orang Pribadi efektif sebesar 84.472. Di sini terlihat bahwa mengapa penerapan $e$-filing masih belum efektif karena masih terdapat perbedaan yang besar antara pelaporan SPT Tahunan dengan menggunakan e-filing dan dengan cara manual. Hal ini disebabkan karena banyak Wajib Pajak yang tidak efektif dan masih banyak yang melaporkan SPT Tahunannya dengan cara manual. Namun meskipun demikian, jumlah penerimaan SPT yang menggunakan e-filing teruslah mengalami kenaikan. Inimerupakan suatu tanda bahwa kebijakan pelaksanaan e-filing telah berjalan dengan baik meskipun masih belum efektif. Akan tetapi sesuai dengan Peraturan yang sudah berlaku sejak 1 April 2018 yaitu Peraturan Menteri Keuangan Nomor 9/PMK.03/2018 bahwa Wajib Pajak yang masih melaporkan SPT Masa dan SPT Tahunan secara manual ke Kantor Pelayanan Pajak harus sudah siap-siap melakukan pelaporan secara online.

Penerapan sistem e-filing di KPP Pratama Malang Selatan ini sudah dilaksanakan sejak tahun 2014, meskipun pada saat itu sistem ini belum terlalu populer dan diwajibkan hanya untuk pegawai kementrian keuangan. Kemudian berkembang dan diwajibkan untuk lebih banyak lagi. Pada saat tahun 2014, KPP Pratama Malang Selatan ini juga tetap menerima 
pelaporan SPT Tahunan secara manual meskipun pelaporan SPT secara e-filing sudah diberlakukan.

Namun kemungkinan besar untuk tahun-tahun berikutnya tidak menutup kemungkinan bahwa KPP Pratama Malang Selatan ini akan menerima pelaporan SPT dengan cara e-filing sesuai dengan peraturan menteri keuangan yang mengatakan bahwa sudah seharusnya siap-siap untuk melakukan pelaporan secara online.

Selain itu pihak KPP Pratama Malang Selatan juga terus berupaya untuk mensosialisasikan tentang e-filing ke tempat-tempat seperti Sekolah agar para Wajib Pajak Orang Pribadi khususnya Pegawai Pemerintah untuk melaporkan SPT Tahunannya menggunakan $e$-filing karena sudah ada aturan yang mengatur tentang pegawai pemerintah harus menggunakan $e$-filing.

.Menurut data yang diperoleh dalam penelitian, Wajib Pajak Orang Pribadi yang terdaftar di KPP Pratama Malang Selatan hingga tanggal 13 November 2018 berjumlah sebesar 113.240.

3. Analisis efektifitas antara target dan realisasi penyampaian SPT Tahunan secara $e$-filing

a. Tahun 2015

$$
\frac{11.130}{8.654} \times 100 \%=129 \%
$$

b. Tahun 2016

$$
\frac{21.037}{20.579} \times 100 \%=102 \%
$$

c. Tahun 2017

$$
\frac{27.308}{19.629} \times 100 \%=139 \%
$$

Tingkat efektifitas Antara Target dan Realisasi Penyampaian SPT Tahunan Dengan Menggunakan E-filing PadaTahun 2015-2017

\begin{tabular}{|c|c|c|c|c|}
\hline \multirow{2}{*}{ Tahun } & \multicolumn{2}{|c|}{ Penggunaan E-filing } & \multirow{2}{*}{ Persentase } & $\begin{array}{c}\text { Tingkat } \\
\text { Efektifitas }\end{array}$ \\
\cline { 2 - 3 } & Target & Realisasi & Tercapai \\
\hline 2015 & 8.654 & 11.130 & $129 \%$ & Tercapai \\
\hline 2016 & 20.579 & 21.037 & $102 \%$ & Tercapai \\
\hline 2017 & 19.629 & 27.308 & $139 \%$ & \\
\hline
\end{tabular}

Sumber : Data diolah, 2019

Berdasarkan tabel di atas dapat disimpulkan bahwa tingkat efektiitas antara target penyampaian SPT Tahunan Wajib Pajak Orang Pribadi yang menggunakan e-filing di KPP Pratama Malang Selatan pada tahun 2015-2017 sudah efektif karena dari tahun ke tahun telah tercapai dengan baik.

Pada tahun 2015 target yang ditentukan sebesar 8.654 dan terealisasi sebesar 11.130 melebihi target sebanyak 2.476, pada tahun 2016 target yag ditentukan sebesar 21.037 dan terealisasi sebesar 20.579 melebihi target hanya sebesar 458, dan juga terjadi pada tahun 2017 di mana target yang ditentukan sebesar 19.629 dan terealisasi sebesar 27.308 di mana ini melebihi target sebanyak 7.679. Hal ini membuktikan bahwa KPP Pratama Malang Selatan sudah efektif berhasil dengan baik untuk mensukseskan penggunaan $e$-filing. 


\section{KESIMPULAN}

Dari hasil penelitian dan pembahasan yang dilakukan dengan teknik analisis data deskriptif kualitatif dan kuantatif maka didapatkan hasil:

1. Kualitas pelayanan yang diberikan oleh fiskus kepada Wajib Pajak sudah bagus sesuai dengan yang diharapkan para Wajib Pajak sehingga bisa meningkatkan kepatuhan Wajib Pajak Orang Pribadi. Hal ini terbukti dari fiskus yang siap membantu para Wajib Pajak yang kesusahan pada saat pelaporan SPT Tahunan menggunakan e-filing, disediakannya ruang asistensi, satgas yang banyak, dan fasilitas komputer dalam jumlah yang banyak. Namun masih banyak Wajib Pajak yang menyampaikan SPT Tahunannya pada saat batas akhir pelaporan SPT Tahunan Orang Pribadi, sehingga terjadi antrian di dalam penggunaan e-filing yang dapat menyebabkan terganggunya pelayanan (server error).

2. Efektifitas penggunaan $e$-filing berdasarkan data Wajib Pajak Orang Pribadi yang efektif disimpulkan bahwa penggunaan e-filing untuk Wajib Pajak Orang Pribadi di KPP Pratama Malang Selatan masih tidak efektif meskipun jumlah Wajib Pajak Orang Pribadi efektif yang terdaftar sudah mengalami peningkatan. Penerapan e-filing masih belum efektif karena masih terdapat Wajib Pajak yang menyampaikan SPT Tahunannya dengan cara manual. Namun jumlah penerimaan SPT Tahunan yang menggunakan e-filing terus mengalami kenaikan.

3. Target dan realisasi penyampaian SPT Tahunan menggunakan e-filingsudah tercapai dengan baik. Hal ini bisa dilihat dari efektifitas penyampaian SPT Tahunan dengan menggunakan e-filing berdasarkan hasil analisis perhitungan tingkat efektifitas target dan realisasi penyampaian SPT Tahunan dengan menggunakan $e$-filingdari tahun 2015-2017 hasilnya sudah tercapai engan baik dan mengalami peningkatan meskipun pada tahun 2016 sempat mengalami penurunan sebesar $27 \%$. Dan untuk tingkat efektifitas yang paling tinggi yaitu pada tahun 2017 sebesar 139\%.

\section{SARAN}

Berdasarkan kesimpulan di atas, ada beberapa saran yang dapat diberikan :

1. KPP Pratama Malang Selatan perlu untuk menjaga kestabilan pelayanan yang bagus seperti ini agar untuk tahun-tahun selanjutnya tingkat pelayanan fiskus kepada Wajib Pajak tidaklah mengalami penurunan melainkan terus mengalami peningkatan. Fiskus perlu untuk menghimbau Wajib Pajak agar menyampaikan SPT Tahunannya sebelum batas akhir penyampaian agar tidak menyebabkan antrian di dalam penggunaan -filingsehingga server error bisa terhindarkan. Selain itu DJP juga perlu untuk meningkatkan jaringan sistem agar tidak terjadi error sehingga kepatuhan Wajib Pajak Orang Pribadi bisa terus mengalami peningkatan lagi.

2. KPP Pratama Malang Selatan dan DJP perlu untuk terus melakukan sosialisasi tentang pengisian $e$ filing dan senantiasa membimbing para Wajib Pajak secara professional tidak hanya secara langsung tetapi juga melalui media sosial, radio, televisi, dan selebaran agar Wajib Pajak terus paham dan mengingat bagaimana cara pelaporan SPT menggunakan e-filingsehingga penyampaian SPT Tahunan secara manual bisa berkurang.

3. KPP Pratama Malang Selatan perlu untuk menjaga kestabilan dan meningkatkan lagi efektifitas penyampaian SPT Tahunan menggunakan e-filingdengan memperhatikan potensi peneriman penyampaian SPT Tahunan menggunakan e-filing agar targetnya selalu terealisasi dengan baik.

\section{DAFTAR PUSTAKA}

Agoes, Estralita. (2007). Akuntansi Perpajakan. Penerbit Salemba Empat.

Agustiningsih. (2016). Pengaruh Penerapan E-Filing, Tingkat Pemahaman Perpajakan Dan Kesadaran Wajib Pajak Terhadap Kepatuhan Wajib Pajak Di KPP Pratama Yogyakarta. Jurnal Nominal.Volume V, No.2, Tahun 2016. 
Andi, dan Dara Novita Sari. (2017). Faktor-Faktor Yang Mempengaruhi Wajib Pajak Orang Pribadi Dalam Penggunaan E-Filing Pada Kpp Pratama Serang. Jurnal Elektronik Fakultas Ekonomi dan Bisnis Untirta.Volume X, Nomor 1, Tahun 2017.

Astuti. (2015). Analisis Penerapan E-Filing Sebagai Upaya Untuk Meningkatkan Kepatuhan Wajib Pajak Dalam Penyampaian Surat Pemberitahuan (SPT) Tahunan Pada Kantor Pelayanan Pajak Pratama Gresik Utara. Jurnal Akuntansi UNESA. Vol 3, No.3, Tahun 2015.

Dyan. (2016). Analisis Faktor-Faktor yang Mempengaruhi Minat Wajib Pajak Dalam Penggunaan EFiling.Artikel Ilmiah Sekolah Tinggi Ekonomi PERBANAS Surabaya.

Elvionita. (2018). Pengaruh Sosialisasi Perpajakan, Kualitas Pelayanan Fiskus, Pemahaman Tentang Peraturan Perpajakan dan Penerapan E-filing Terhadap Kepatuhan Wajib Pajak (Studi Kasus Pada Wajib Pajak Orang Pribadi UMKM di KPP Pratama Pekanbaru Senapelan). Jurnal Online Mahasiswa Fakultas Ekonomi. Vol 1, No 1, Tahun 2018

Erawati, Teguh dan Rita Ratnasari. (2018). Pengaruh Penerapan E-filing Terhadap Kepatuhan Wajib Pajak Dalam Menyampaikan SPT Tahunan Dengan Kepuasan Kualitas Pelayanan Sebagai Variabel Intervening (Studi Empiris Di Kabupaten Gunungkidul). Jurnal Akuntansi Universitas Sarjanawiyata Tamansiswa. Vol 6, No.1, Tahun 2018.

Ganggut. (2015). Efektifitas Implementasi e-Filing Dalam Praktik Penerimaan SPT Tahunan Wajib Pajak Orang Pribadi di KPP Pratama Singosari.Skripsi FEB UNMER MALANG.

Handayani Kartika Ratna dan Sihar Tambun. (2016). Pengaruh Penerapan Sistem E-Filing Dan Pengetahuan Perpajakan Terhadap Kepatuhan Wajib Pajak Dengan Sosialisasi Sebagai Variabel Moderating (Survei Pada Perkantoran Sunrise Garden di Wilayah Kedoya, Jakarta Barat). Media Akuntansi Perpajakan.Vol 1, No.2, Tahun 2016.

Indriantoro dan Bambang Supomo. (2009). Metodologi Penelitian Bisnis Untuk Akuntansi Dan Manajemen. Penerbit BPEE Yogyakarta

Instruksi Presiden Republik Indonesia Nomor 3 Tahun 2003 Tentang Kebijakan dan Strategi Nasional Pengembangan E-Government.

Kirana. (2010). Analisis Perilaku Penerimaan Wajib Pajak Terhadap Penggunaan e-filling (kajian empiris wilayah Kota Semarang. Skripsi FE UNDIP.

Mardiasmo. (2018). Perpajakan. Penerbit ANDI Yogyakarta, Edisi Revisi 2018.

Nugraha. (2010). Analisis Modernisasi Pelayanan Pajak Dan E-System Pada KPP Pratama Malang Selatan. Skripsi FEB UNMER MALANG.

Peraturan Direktorat Jenderal Pajak Nomor PER 47/PJ/2008 Tentang Tata Cara Penyampaian Pemberitahuan Perpanjangan Surat Pemberitahuan Tahunan Secara Elektronik (e-filing) Melalui Perusahaan Penyedia Jasa Aplikasi (ASP).

Peraturan Direktur Jenderal Pajak Nomor PER-01/PJ/2014 Tentang Tata Cara Penyampaian Surat Pemberitahuan Tahunan Bagi Wajib Pajak Orang Pribadi yang Menggunakan Formulir $1770 \mathrm{~S}$ atau 1770SS Secara E-filing Melalui Website Direktorat Jenderal Pajak (www.pajak.go.id).

Peraturan Jenderal Pajak Nomor PER-20/PJ/2012 Tentang Tata Cara Penyampaian Surat Pemberitahuan Tahunan Bagi Wajib Pajak Orang Pribadi.

Peraturan Jenderal Pajak Nomor PER-26/PJ/2012 Tentang Tata Cara Penerimaan Dan Pengelolaan Surat Pemberitahuan Tahunan.

Peraturan Jenderal Pajak Nomor PER-38/PJ/2013 Tentang Tata Cara Pendaftaran dan Pemberian Nomor Pokok Wajib Pajak, Pelaporan Usaha dan Pengukuhan Pengusaha Kena Pajak, Penghapusan Nomor Pokok Wajib Pajak dan Pencabutan Pengukuhan Pengusaha Kena Pajak, Serta Perubahan Data dan Pemindahan Wajib Pajak.

Peraturan Menteri Keuangan Nomor 55/PMK.01/2007 Tentang Perubahan Atas Peraturan Menteri Keuangan Nomor 132/PMK.01/2006 Tentang Organisasi dan Tata kerja Instansi Vertikal Direktorat Jenderal Pajak Menteri Keuangan. 
Peraturan Menteri Keuangan Republik Indonesia Nomor 206.2/PMK.01/2014 Tentang Organisasi dan Tata Kerja Instansi Vertikal Direktorat Jenderal Pajak.

Peraturan Menteri Keuangan Republik Indonesia Nomor 9/PMK.03/2018 Tentang Perubahan Atas Peraturan Menteri Keuangan Nomor 243/PMK.03/2014 Tentang Surat Pemberitahuan (SPT).

Rahayu, Siti Kurnia. (2017). Perpajakan Konsep Dan Aspek Formal. Rekayasa Sains, Bandung.

Rahayu. (2016). Efektivitas Penggunaan E-System Dalam Pelayanan Perpajakan Terhadap Ketepatan Pelaporan E-filing (studi kasus di KPP Pratama Batu). Skripsi FEB UNMER MALANG.

Refiaty. (2018). Evaluasi Kualitas Pelayanan Dan Kepatuhan Wajib Pajak Untuk Meningkatkan Penerimaan Pajak (Studi Empiris Pada KPP Pratama Malang Selatan). Skripsi FEB UNMER MALANG.

Restikasari, (2018). Pengaruh Layanan E-Filing Terhadap Tingkat Kepuasan Pelaporan SPT Tahunan Di Kantor Pelayanan Pajak Pratama Kediri. Tugas Akhir Perpajakan STAN.

Sapriadi. (2013). Pengaruh Kualitas Pelayanan Pajak, Sanksi Pajak, Dan Kesadaran Wajib Pajak Terhadap Kepatuhan Wajib Pajak Dalam Membayar PBB (Pada Kecamatan Selupu Rejang). Jurnal Akuntansi UNP. Vol 1, No 1, Tahun 2013.

Solikah Mar'atus dan Dian Kusumaningtyas. (2017). E-filing Pada Kantor Pelayanan Pajak Pratama Kota Kediri. Jurnal Ekonomi Universitas Kadiri. Vol 2, No.2, Tahun 2017.

Suherman Maman dan Medina Almunawwaroh. (2015). Pengaruh Penerapan E-filing Terhadap Kepatuhan Wajib Pajak Dalam Penyampaian Surat Pemberitahuan (SPT) Tahunan Pada Kantor Pelayanan Pajak Pratama Kota Tasikmalaya. Media Riset Akutansi, Auditing \& Informasi. Vol 15, No.1, Tahun 2015

Tumuli Apriliani Kasandra, Jullie J. Sondakh, dan Heince R.N Wokas. (2016). Analisis Penerapan E-SPT Dan E-Filing Dalam Upaya Peningkatan Kepatuhan Wajib Pajak (Studi Kasus Di Kantor Pelayanan Pajak Pratama Manado). Jurnal Riset Ekonomi, Manajemen, Bisnis dan Akuntansi. Vol 4, No.3, Tahun 2016.

Undang-Undang Republik Indonesia Nomor 25 Tahun 2009 Pasal 5 Ayat 1 Tentang Pelayanan Barang Publik Dan Jasa Publik Serta Pelayanan Administrasi.

Undang-Undang Republik Indonesia Nomor 3 Tahun 2003 Tentang Kebijakan Dan Strategi Nasional Pengembangan E-Government. 